\title{
Sofralık Üzüm Çeşitlerinde İkinci Ürün (Neferiye) Salkımlarının Bazı Genel Karakteristiklerinin Belirlenmesi
}

\begin{abstract}
Alper Dardeniz ${ }^{1^{*}}$
Mehmet Ali Gündoğdu²

Esra Şahin ${ }^{3}$

Baboo $\mathrm{Ali}^{4}$

${ }^{1,2,3}$ ÇOMÜ Ziraat Fakültesi, Bahçe Bitkileri Bölümü. 17100/Çanakkale.

${ }^{4}$ ÇOMÜ Ziraat Fakültesi, Tarla Bitkileri Bölümü. 17100/Çanakkale.

*Sorumlu yazar: adardeniz@ comu.edu.tr

${ }^{1}$ https://orcid.org/0000-0003-3480-6620, ${ }^{2}$ https://orcid.org/0000-0002-5802-5505, ${ }^{3}$ https://orcid.org/0000-0003-3850-

3407, ${ }^{4}$ https://orcid.org/0000-0002-6989-7018

Geliş Tarihi: 16.12.2019

Kabul Tarihi: 18.05.2020

\section{$\ddot{O} z$}

Bu araştırma, 'Çanakkale' ili ÇOMÜ Dardanos Yerleşkesi 'Ziraat Fakültesi Çiftliği Bitkisel Üretim ve Araştırma Birimi' 'Sofralık Üzüm Çeşitleri Araştırma ve Uygulama Bağı' içerisinde yer alan 'Yalova İncisi', 'Cardinal', 'Amasya Beyazı' ve 'Kozak Beyazı' üzüm çeşitlerinde, ikinci ürün (neferiye) salkımlarının bazı genel karakteristiklerinin belirlenmesi amacıyla 2012, 2013 ve 2015 yıllarında 3 yıl süreyle yürütülmüştür. Üzüm çeşitlerinin ilk (ana) ürün ve ikinci ürün (neferiye) salkımlarının hasatları çeşitlerin ticari olgunluk dönemlerinde farklı tarihlerde yapılmış ve bu kapsamda; salkım eni (cm), salkım boyu (cm), salkım sıklığı (1-9), ortalama salkım ağırlı̆̆ (g), tane ağırlığı (g), SÇKM (\%), pH, \%asitlik (\%) ve olgunluk indisi (\%SÇKM/\%asitlik) parametreleri incelenerek bazı önemli farklılıkların oluştuğu saptanmıştır. Üzüm çeşitlerinin hepsinde salkım eni, salkım boyu, ortalama salkım ağırlığı ve tane ağırlığına ait en yüksek değerler ilk (ana) ürünlerde tespit edilmiş, en yüksek salkım sıklığı değerleri ise ikinci ürünlerden (neferiye) elde edilmiştir. 'Yalova İncisi' ve 'Cardinal' üzüm çeşitlerinde en yüksek \%SÇKM değeri ikinci ürünlerde saptanırken, 'Kozak Beyazı' üzüm çeşidinde ilk (ana) ürünlerde belirlenmiştir. 'Cardinal' ve 'Kozak Beyazı' üzüm çeşitlerinde ilk (ana) ürünlerin olgunluk indisi değerleri, ikinci ürünlerin (neferiye) olgunluk indisi değerlerine kıyasla önemli düzeyde yüksek bulunmuştur.
\end{abstract}

Anahtar Kelimeler: Sofralık üzüm, ilk (ana) ürün, ikinci ürün (neferiye), üzüm kalitesi, Çanakkale

\section{Determination of Some General Characteristics of the Second Crop Clusters in Table Grapes \\ Abstract}

This research was carried out on the 'Yalova Incisi', 'Cardinal', 'Amasya Beyazı' and 'Kozak Beyazı', grape varieties which were included in the 'Research Vineyard of Table Grape Varieties' 'Faculty of Agriculture's Plant Production and Research Farm' in Dardanos Campus of COMU. This study was conducted for 3 years in 2012, 2013 and 2015 in order to determine some general characteristics of second crop clusters. The first (main) and second crop clusters of grape varieties were harvested different dates in the commercially maturity periods of grape varieties. Cluster width $(\mathrm{cm})$, cluster length $(\mathrm{cm})$, cluster compactness (1-9), average cluster weight (g), berry weight (g), TSS (\%), pH, acidity (\%) and maturity index (\% TSS/\%acidity) parameters were investigated and significant differences were determined. In all grape varieties, the highest values of cluster width, cluster length, average cluster weight and berry weight were determined in first (main) crops. The highest cluster compactness values were obtained from second crops. While 'Yalova Incisi' and 'Cardinal' grape varieties had the highest \%TSS value in the second crops, it was found in first (main) crops of 'Kozak Beyazı' grape variety. In 'Cardinal' and 'Kozak Beyazı' grape varieties, the maturity index values of first (main) crops were significantly higher than the second crops.

Keywords: Table grapes, first (main) crop, second crop, grape quality, Çanakkale

\section{Giriş}

Yazlık sürgünlerin boğumlarında (nodyum), yaprak koltuklarındaki kış gözleriyle aynı gelişim devresi içerisinde oluşan ve erkenci dal veya koltuk sürgünleri adı verilen ikinci derecedeki sürgünleri meydana getiren gözlere (tomurcuk) aktif göz veya aktif tomurcuk adı verilmektedir. Bu koltuk sürgünleri aynı zamanda yan sürgün, lateral sürgün, erkenci dal, ikinci derecede yaz sürgünü ve mahmuz gibi farklı isimlerle de adlandırılmaktadır. Koltuk sürgünleri, üzerinden çıktıkları yazlık sürgünlere oldukça benzer bir gelişim göstermektedir (Çelik, 2011; Dardeniz, 2011, Türker ve Dardeniz, 2014). Bununla birlikte, erkenci dal olarak da isimlendirilen koltuk sürgünlerinin morfolojik 
yapılarında, ana sürgüne kıyasla bazı farklılıklar bulunmaktadır. Örneğin; koltuk sürgünlerinin dip kısmında, yazlık ana sürgünde iki adet olarak bulunan pul şeklindeki yaprakçık tektir. Ayrıca koltuk sürgünlerinin sülükleri dipten itibaren 2. boğumdan başlayarak oluşurken, yazlık sürgünlerin sülükleri 5.-6. boğumdan itibaren meydana gelmektedir (Çelik ve ark., 1998; A ğaoğlu, 1999).

Yazlık sürgünlerin üzerindeki kısa sürgünler olan koltuk sürgünlerinin oluşumu üzüm tür ve çeşitlerine, yazlık sürgünün gelişim kuvvetine, uç ve tepe alma uygulamaları gibi tepe baskınlığının (apikal dominansi) ortadan kaldırılmasına yönelik uygulamalara ve sürgünün dik veya yatay yönlendirilmesine bağlı olarak farklılık arz edebilmektedir (Çelik ve ark., 1998; Ağaoğlu, 1999; Çelik, 2011). Koltuk sürgünlerinin gelişim güçleri, bulundukları boğum seviyesiyle de ilişkilidir (Ağaoğlu, 1999). Koltuk sürgünü oluşumu, dik şekilde geliştirilen yazlık sürgünlerin dip boğumlarında daha azken, yatay olarak yönlendirilmiş olan yazlık sürgünlerin her bir yaprak koltuğundan, aktif tomurcuğun sürmesiyle aynı kuvvette bir koltuk sürgünü teşekkül etmektedir.

Koltuk sürgünlerindeki kış gözlerinde çiçek salkımı oluşumu sekonder tomurcuk, kör (baziler) göz ve hatta kış gözlerindeki gibi farklı fizyolojik olaylar sonucunda gerçekleşmekte ve bu oluşum çok kısa sürede tamamlanmaktadır. Koltuk sürgünündeki gözlerin ayrımı ve salkım taslaklarının oluşumu çevre şartlarının optimum olmasıyla ilgilidir. Koltuk sürgünlerindeki gözlerin en büyük avantajı, oluştukları zamanın iklim koşullarının en uygun olduğu dönem olan yaz aylarına denk gelmesidir. Bu durum, koltuk sürgünlerindeki dip kısma yakın gözlerin morfolojik ayrımları ile salkımlar meydana getirilmesi olasılığını arttırmaktadır (Ağaoğlu, 2002). Bununla birlikte Scheu (1950)'ya atfen Ağaoğlu (2002), koltuk sürgünlerindeki gözlerin verimli olup olmadıkları hakkında farklı görüşler olduğunu ifade etmektedir.

Antcliff (1958)'e atfen Ağaoğlu (2002), koltuk yapraklarında meydana gelen büyüme düzenleyici maddelerin kış gözleri üzerindeki olumlu etkilerinden dolayı, Sultani Çekirdeksiz üzüm çeşidinde koltuk sürgünü taşıyan boğumlardaki kış gözü verimliliğinin, koltuk sürgünü taşımayanlara kıyasla daha yüksek ve salkım taslaklarının da daha büyük olduğunu bildirmektedir.

Yazlık sürgünler üzerinde geç tarihte sürerek çoğunlukla daha zayıf bir gelişim ve odunlaşma (pişkinleşme) gösteren koltuk sürgünleri şiddetli kış donları sonucunda omcaların üzerinden dökülebilmekte, bununla birlikte iyi gelişip odunlaşmış olan koltuklar ise donlardan etkilenmemektedir. Özellikle yarma aşının ardından, oldukça kuvvetli bir gelişim gösteren yazlık sürgünlerin kuvvetli gelişen koltuklardan yararlanılmakta ve bu durum omcalara daha erken şekil kazandırılmasına olanak sağlayabilmektedir. Böylelikle 3-4 yılda oluşturulabilen terbiye şekilleri, koltuklar üzerlerindeki kış gözlerinin kullanımıyla 2-3 yılda tamamlanabilmektedir.

Bununla birlikte, kuvvetli gelişen koltuk sürgünlerinin omcaların üzerinde ürün dalı olarak bırakılıp bırakılamayacakları konusu tartışmalıdır (Ağaoğlu, 2002). Kısmalı ve Ilgın (1992), çekirdeksiz üzüm bağlarında yürüttükleri bir araştırmada kontrol olarak 18'er gözlü yıllık dallar kullanmışlar, 3'er gözlü yıllık dal ve 3. boğumdan çıkan 15'er gözlü koltuk (toplam 18 göz) ile 9'ar gözlü yıllık dal ve 9. boğumdan çıkan 9'ar gözlü koltuk arasında, 18'er gözlü 8 farklı koltuklu kombinasyonu incelemişlerdir. Sonuç olarak, koltuk sürgünlerinden ürün dalı olarak faydalanabilmenin mümkün olduğu belirlenmiş ve Ege Bölgesi çekirdeksiz üzüm bağlarında uzun bırakılan ürün dallarının dip gözleri uyanmadığında, yöre bağcıları tarafından bu kısımdan oluşan ve kuvvetli olarak gelişim gösteren koltuk sürgünlerinin ürün dalı olarak kullanılması uygulamasını olumlu bulmuşlardır.

Koltuk sürgünleri genellikle verimsiz olup, bazı üzüm çeşitlerinde koltuk sürgünlerinin üzerinden ikinci ürün (neferiye) adı verilen salkımlar meydana gelebilmektedir. Koltuk sürgünleri üzerinde oluşan bu ikinci ürün salkımlarının olgunlaşması, o yörenin EST’1 (etkili sıcaklık toplamı) ile yakından ilişkilidir (Ağaoğlu, 2002; Çelik ve ark., 1998; Türker ve Dardeniz, 2014). Erkenci ve orta mevsimde olgunlaşan üzüm çeşitlerinin neferiyeleri ancak EST'1 1.800 gün/derecenin üzerindeki ekolojilerde olgunlaşabilmekte ve farklı amaçlar doğrultusunda değerlendirilmektedir (Çelik ve ark., 1998). Bazı üzüm çeşitlerinde oldukça fazla neferiye oluşumu gözlenirken, bazı üzüm çeşitlerinden kısıtlı veya yok denecek kadar az neferiye alınabilmektedir. Bazı üzüm çeşitlerindeki ikinci ürünün (neferiye), ilk (ana) ürünün neredeyse 1/4'ünü teşkil edebildiği belirtilmektedir (Winkler, 1974). Genellikle; Alphonse Lavallée, Amasya Beyazı, Cabernet Sauvignon, Carignane, Hafizali, Kozak Beyazı, Öküzgözü, Uslu ve Yalova İncisi gibi üzüm çeşitleri daha fazla neferiye oluşturma eğiliminde olan çeşitlerdir. Ağaoğlu (1969) tarafindan yapılan bir çalışmada, Öküzgözü ve Furmint üzüm çeşitlerinde çok sayıda neferiye oluştuğu ve bunların olgunlaşabildiği belirtilmiştir. 
Altı farklı sofralık üzüm çeşidinde yürütülen bir araştırmada, YDKA (yüksek düzeyde koltuk alma), NDKA (normal düzeyde koltuk alma) ve YDKB (yüksek düzeyde koltuk bırakma) uygulamaları gerçekleştirilmiştir. Özellikle araştırmanın ikinci yılında (2013), YDKB uygulaması omcaların potansiyelini yükselterek önemli verim artışına neden olurken, YDKA uygulaması bütün üzüm çeşitlerinde omca potansiyelinde azalmaya yol açarak üzüm verimini düşürmüştür. YDKB uygulamasının sofralık üzüm çeşitlerinde üzüm verimini yükselterek, kaliteli ve daha erkenci üzüm üretimine katkı sağlayabileceği belirtilmiştir (Türker ve Dardeniz, 2014). Yalova İncisi üzüm çeşidinde yürütülen bir araştırmada, NTB+YDKB (Normal tarihte budama + yüksek düzeyde koltuk bırakma) uygulamasında, yaprak alanı ve omca potansiyeli artışı neticesinde hem ortalama verim hem de üzüm kalitesi ve olgunluğunda oldukça tatminkâr artışlar sağlanmıştır (Sezen ve Dardeniz, 2015). Koblet ve Perret (1971), Bouvier ve Riesling x Sylvaner melezi üzüm çeşitlerinde ikinci ürün (neferiye) taşıyan koltukların özümleme ürünlerini neferiyeleri için kullandıkları halde, neferiyesiz koltuk sürgünlerinin asimilat maddeleri ana sürgün salkımlarına yönlendirdiklerini belirlemişlerdir.

Üzüm çeşitlerinde yapraklar tarafından sentezlenen özümleme ürünleri hasat dönemi yaklaştıkça çoğunlukla ilk (ana) ürünlerin olgunluğuna harcanmaktayken, bir taraftan başta ana kök olmak üzere ana gövde, ana kol(lar) ve başlar gibi omcanın yaşlı kısımlarına yönlendirilerek depo edilmekte ve yazlık sürgünlerin orta-dip kısımlarından itibaren odunlaşmasında kullanılmaktadır. İlk (ana) ürünün omcalar üzerinden hasat edilip uzaklaştırılmasıyla birlikte ürün yükünün azalmasıyla, özümleme ürünlerinin yazlık sürgünler ile yaşlı kısımlarda nişasta şeklinde depo edilmesi hızlanırken, özümleme ürünlerinin bir kısmı da az miktardaki neferiyenin olgunlaşmasına harcamaktadır. $\mathrm{Bu}$ nedenle neferiyeler, ilk (ana) ürün hasadının ardından yükünü üzerinden atmış olan omcalarda oldukça kısa süre (3-5 hafta) içerisinde ikinci bir ürün olarak olgunlaşmaktadır. Neferiye salkımları omcalar üzerinde yeterince bekletildiklerinde, ilk (ana) ürün salkımlarının tanelerine kıyasla oldukça gevrek, yüksek aromalı ve lezzetli taneler meydana getirebilmekte, bu nedenle bazı yörelerimizde tüketiciler tarafindan beğeniyle tüketilmektedir.

Neferiyeler, bağdan ilk (ana) ürünün hasadının ardından olgunlaşmaya başladıklarından, bağın son bekçi salkımları anlamındaki nefer (asker) ve neferge vb. gibi farklı yöresel isimlerle de adlandırılmaktadırlar. Aktif tomurcuktan gelişen koltuk sürgünlerinde çiçek salkımlarının oluşumu, tane tutumunun gerçekleşmesi ve ilk (ana) ürünün hasadının ardından neferiyelerden ikinci ürünün alınması oldukça kısa bir periyotta tamamlanmakta, bağda doğuşun az olduğu yıllarda koltuk sürgünleri üzerinde daha fazla ve daha iri neferiye salkımlarının meydana geldiği gözlemlenmektedir.

$\mathrm{Bu}$ araştırmada, Çanakkale ili şartlarında yetiştirilen sofralık üzüm çeşitlerinde ikinci ürün (neferiye) salkımlarının bazı genel karakteristiklerinin belirlenmesi amaçlanmıştır.

\section{Materyal ve Metot}

Bu araştırma, Çanakkale ili ÇOMÜ Dardanos Yerleşkesi 'Ziraat Fakültesi Çiftliği Bitkisel Üretim ve Araştırma Birimi' 'Sofralık Üzüm Çeşitleri Araştırma ve Uygulama Bağı' içerisinde yer alan Yalova İncisi, Cardinal, Amasya Beyazı ve Kozak Beyazı üzüm çeşitlerinde, ikinci ürün (neferiye) salkımlarının bazı genel karakteristiklerinin belirlenmesi amaciyla 2012, 2013 ve 2015 yıllarında 3 yıl süreyle yürütülmüştür. Ağustos ayının başında Yalova İncisi, Ağustos ayının ortasında Cardinal, Eylül ayının başında Amasya Beyazı ve Eylül ayının ortasında Kozak Beyazı üzüm çeşitlerinden ilk (ana) ürünlerin hasadının ardından, 3-4 hafta içerisinde neferiyelerinin hasadı gerçekleştirilmiş ve ilk (ana) ürün ile ikinci ürün salkımlarının bazı genel karakteristikleri belirlenerek mukayese edilmiştir. Bu kapsamda; salkım eni (cm), salkım boyu (cm), salkım sıklığ 1 (1-9) (Anonim, 1985), ortalama salkım ağırlığı (g), tane ağırlığı (g), SÇKM (\%), pH, asitlik (\%) ve olgunluk indisi (\%SÇKM/\%asitlik) parametreleri incelenmiştir.

Bağ parselinde kuş zararı görülmesi nedeniyle, üzüm çeşitlerinin ben düşme tarihleriyle birlikte ilk (ana) ürünlerin üzerleri file örtü materyali ile örtülmüş, bu şekilde omca başına ilk (ana) ürün verimi (kg/omca) sağlıklı olarak saptanabilmiştir. Ancak, daha üst kısımlarda kalan ikinci ürünlerin üzerleri örtülemediğinden ve yaz budamaları kapsamında bazı koltuk sürgünlerinin alımı gerçekleştirilmiş olduğundan, üzüm çeşitlerinde ikinci ürünlerin verim $(\mathrm{kg} / \mathrm{omca})$ değerleri sağlıklı olarak belirlenememiş ve ilk (ana) ürün ile ikinci ürün kıyaslamasına gidilememiştir. Üzüm çeşitlerinin ikinci ürün (neferiye) salkımları üzerinde incelenen parametreler, üzerlerinde kuş zararı bulunmayan ikinci ürün (neferiye) salkımlarının bağdan özenle seçilmesiyle saptanmıştır. 
Tesadüf parselleri deneme desenine göre 4 tekerrürlü olarak kurulan araştırmadan elde edilmiş olan veriler; 'SAS ${ }^{\circledR}$ ver. 9.0' istatistik paket programı kapsamında varyans analizine tabi tutulmuş, uygulamalara ait ortalama değerler LSD çoklu karşılaştırma testine göre değerlendirilmiştir.

\section{Bulgular ve Tartışma}

Sofralık üzüm çeşitlerinde ikinci ürün (neferiye) salkımlarının bazı genel karakteristiklerinin belirlenmesi amacıyla 2012, 2013 ve 2015 y1llarında yürütülen bu araştırmadan elde edilen bulgular Çizelge 1., Çizelge 2., Çizelge 3. ve Çizelge 4.'te sunulmuştur.

Çizelge 1.'deki üç yılın ortalama değerlerine göre; sırasıyla Yalova İncisi, Cardinal, Amasya Beyazı ve Kozak Beyazı üzüm çeşitlerinde ilk (ana) ürünün salkım eni $(9,64 \mathrm{~cm}, 9,76 \mathrm{~cm}, 11,04 \mathrm{~cm}$ ve $10,77 \mathrm{~cm})$, ikinci ürünün salkım enine $(8,31 \mathrm{~cm}, 6,85 \mathrm{~cm}, 9,38 \mathrm{~cm}$ ve $9,15 \mathrm{~cm})$ kıyasla önem oluşturmuştur.

İkinci ürünlerde çeşitler arasında en genişs salkım enine sahip salkımlar Amasya Beyazı $(9,38$ $\mathrm{cm})$ ve Kozak Beyazı $(9,15 \mathrm{~cm})$ üzüm çeşitlerinden, en dar salkımlar ise Cardinal $(6,85 \mathrm{~cm})$ üzüm çeşidinden elde edilmiş, Yalova İncisi üzüm çeşidi $(8,31 \mathrm{~cm})$ arada başka bir grubu oluşturmuştur. İlk (ana) ürünler bazında çeşitler arasındaki salkım eni değerlerinde, en geniş salkımlar Amasya Beyazı $(11,04 \mathrm{~cm})$ ve Kozak Beyazı $(10,77 \mathrm{~cm})$ üzüm çeşitlerinde, en dar salkımlar ise Yalova İncisi $(9,64$ $\mathrm{cm})$ ve Cardinal üzüm çeşitlerinde $(9,76 \mathrm{~cm}$ ) belirlenmiştir (Çizelge 1.).

Sırasıyla Yalova İncisi, Cardinal, Amasya Beyazı ve Kozak Beyazı üzüm çeşitlerinde salkım boyları ilk (ana) ürünlerde $(15,62 \mathrm{~cm}, 18,44 \mathrm{~cm}, 17,95 \mathrm{~cm}$ ve $18,20 \mathrm{~cm})$ uzunken, buna kiyasla ikinci ürünlerde $(13,15 \mathrm{~cm}, 9,58 \mathrm{~cm}, 10,32 \mathrm{~cm}$ ve $9,85 \mathrm{~cm})$ daha kısadır. İkinci üründe en uzun salkımlar Yalova İncisi üzüm çeşidinde $(13,15 \mathrm{~cm})$, en kısa salkımlar ise sırasıyla Cardinal $(9,58 \mathrm{~cm})$, Kozak Beyazı $(9,85 \mathrm{~cm})$ ve Amasya Beyazı $(10,32 \mathrm{~cm})$ üzüm çeşitlerinde tespit edilmiştir. İlk (ana) ürünlerde bunun tam tersi görülmüss salkım boyu bakımından sırasıyla Cardinal $(18,44 \mathrm{~cm})$, Kozak Beyazı $(18,20 \mathrm{~cm})$ ve Amasya Beyazı $(17,95 \mathrm{~cm})$ üzüm çeşitleri en uzun salkımlara sahipken, Yalova İncisi $(15,62 \mathrm{~cm})$ üzüm çeşidinden en kısa salkımlar elde edilmiştir (Çizelge 1.).

Sırasıyla Yalova İncisi ve Amasya Beyazı üzüm çeşidinde salkım sıklığı ikinci ürünlerde (6,98 ve 6,95) ilk (ana) ürüne (6,17 ve 6,22) nazaran önem oluşturmuştur. Bu durumun, Ağaoğlu (2002)'nun da belirtmiş olduğu gibi ikinci ürün salkımlarının tane tutum tarihlerinin ilk (ana) ürün salkımlarına kıyasla daha geç bir tarihte ve optimum iklim şartlarında gerçekleşmiş olmasından kaynaklandığı düşünülmektedir. Çeşitler arasında ikinci ürünlerde salkım sıklığı bakımından en sık salkımlar Yalova İncisi $(6,98)$ ve Amasya Beyazı $(6,95)$ üzüm çeşitlerinde, en seyrek salkımlar ise Cardinal $(5,70)$ ve Kozak Beyazı $(6,26)$ üzüm çeşitlerinde tespit edilmiştir. Yine salkım sıklığı bakımından ilk (ana) ürünlerde en sık salkımları Amasya Beyazı $(6,22)$, Kozak Beyazı $(6,18)$ ve Yalova İncisi $(6,17)$ üzüm çeşitleri oluştururken, Cardinal $(5,65)$ üzüm çeşidinde en seyrek salkımlar meydana gelmiştir (Çizelge 1.).

Çizelge 2.'deki üç yılın ortalama değerlerine göre; ortalama salkım ağırlı̆̆ında sırasıyla Yalova İncisi, Cardinal, Amasya Beyazı ve Kozak Beyazı üzüm çeşitlerinde ilk (ana) ürünler $(286,7 \mathrm{~g}, 276,3 \mathrm{~g}, 313,3 \mathrm{~g}$ ve $359,9 \mathrm{~g})$, ikinci ürünlere $(156,0 \mathrm{~g}, 71,31 \mathrm{~g}, 153,8 \mathrm{~g}$ ve $137,8 \mathrm{~g})$ kiyasla önemli bulunmuştur. Çeşitler bazında ikinci ürünlerde en yüksek ortalama salkım ağırlı̆̆ Yalova İncisi (156,0 g), Amasya Beyazı (153,8 g) ve Kozak Beyazı (137,8 g) üzüm çeşitlerinden elde edilmiş, Cardinal üzüm çeşidi ise $71,31 \mathrm{~g}$ ile en düşük ortalama salkım ağırlı̆̆ını oluşturmuştur. İlk (ana) ürünlerde en yüksek ortalama salkım ağırlı̆̆ Kozak Beyazı $(359,9$ g) üzüm çeşidinde saptanırken, Amasya Beyazı (313,3 g), Yalova İncisi $(286,7 \mathrm{~g})$ ve Cardinal $(276,3 \mathrm{~g})$ üzüm çeşitleri ikinci grupta yer almıştır.

Sırasıyla Yalova İncisi, Cardinal, Amasya Beyazı ve Kozak Beyazı üzüm çeşitlerinde ilk (ana) ürünlere ait tane ağırlıkları $(5,34 \mathrm{~g}, 6,31 \mathrm{~g}, 4,12 \mathrm{~g}$ ve 5,29), ikinci ürünlerin tane ağırlığına $(4,04 \mathrm{~g}$, $3,94 \mathrm{~g}, 3,35 \mathrm{~g}$ ve $3,87 \mathrm{~g}$ ) kıyasla önem oluşturmuştur. İkinci ürünlerde çeşitler arasında en yüksek tane ağırlığına sahip çeşitler sırasıyla Yalova İncisi $(4,04$ g), Cardinal $(3,94$ g) ve Kozak Beyazı $(3,87$ g) üzüm çeşitleri olarak belirlenmiş, Amasya Beyazı $(3,35 \mathrm{~g})$ üzüm çeşidi diğer çeşitlere göre daha düşük tane ağırlı̆̆ 1 oluşturmuştur. İlk (ana) ürünlerde en yüksek tane ağırlığı Cardinal $(6,31 \mathrm{~g})$ üzüm çeşidinde, en düşük tane ağırlığı ise Amasya Beyazı (4,12 g) üzüm çeşidinde bulunmuş, Yalova İncisi $(5,34 \mathrm{~g})$ ve Kozak Beyazı $(5,29 \mathrm{~g})$ üzüm çeşitleri ise arada farklı bir grubu oluşturmuştur (Çizelge 2). 
Araştırma kapsamında çeşitlerin şıra özellikleri de incelenmiş olup, \%SÇKM, pH, \%asitlik ve olgunluk indisi (\%SÇKM/\%asitlik) parametreleri arasında önemli farklılıklar belirlenmiştir. Çizelge 3.'teki üç yıllık ortalama değerlerde; Yalova İncisi ve Cardinal üzüm çeşitlerinin ikinci ürünlere ait tanelerinin \%SÇKM değerleri $(\% 15,50$ ve \%17,18), ilk (ana) ürünlere ait \%SÇKM değerlerine (\%14,20 ve \%16,31) nazaran daha yüksek bulunmuştur. Kozak Beyazı üzüm çeşidinde ise ilk (ana) ürün $(\% 20,37)$, ikinci ürüne $(\% 18,61)$ göre önem oluşturmuştur. İkinci ürünlerde en yükssek \%SÇKM değeri Kozak Beyazı $(\% 18,61)$ üzüm çeşidinde, en düşük \% SÇKM değeri ise Yalova İncisi $(\% 15,50)$ ve Amasya Beyazı $(\% 16,03)$ üzüm çeşitlerinde tespit edilmiş, Cardinal $(\% 17,18)$ üzüm çeşidi ise arada başka bir grubu teşkil etmiştir. İlk (ana) ürünlerde \%20,37 ile Kozak Beyazı en yüksek \%SÇKM değerine sahipken, \%14,20 ile Yalova İncisi en düşük \%SÇKM değerine sahip çeşit olmuş, Cardinal (\%16,31) ve Amasya Beyazı $(\% 16,76)$ üzüm çeşitleri arada başka bir grubu oluşturmuştur.

Cardinal, Amasya Beyazı ve Kozak Beyazı üzüm çeşitlerinde ilk (ana) ürünlerin pH değerleri $(3,69,3,68$ ve 3,77$)$, ikinci ürünlerin $\mathrm{pH}$ değerlerinden $(3,47,3,46$ ve 3,53$)$ daha yüksek bulunmuştur. İkinci ürünlerdeki $\mathrm{pH}$ değerleri incelendiğinde, en yüksek $\mathrm{pH}$ değeri Yalova İncisi $(3,58)$ üzüm çeşidinde, en düşük ise sırasıyla Amasya Beyazı $(3,46)$ ve Cardinal $(3,47)$ üzüm çeşitlerinde tespit edilmiş, Kozak Beyazı üzüm çeşidi 3,53 ile ara grupta yer almıştır. İlk (ana) ürünlerde Kozak Beyazı $(3,77)$ üzüm çeşidinin pH değeri, Yalova İncisi $(3,62)$, Cardinal $(3,69)$ ve Amasya Beyazı $(3,68)$ üzüm çeşitlerine kıyasla önemli bulunmuştur (Çizelge 3).

Çizelge 4.'teki üç yıllık ortalama değerlerde; Cardinal ve Kozak Beyazı üzüm çeşitlerinde $\%$ asitlik değerleri ikinci ürünlerde $(\% 0,816$ ve $\% 0,629)$ ilk (ana) ürünlere $(\% 0,643$ ve $\% 0,468)$ göre daha yüksek bulunmuştur. Yalova İncisi ve Amasya Beyazı üzüm çeşitlerinde ise ikinci ve ilk (ana) ürünler arasında önemli bir farklılık belirlenememiştir. İkinci ürünlerde \%asitlik değerleri Cardinal $(\% 0,816)$ üzüm çeşidinde, Yalova İncisi $(\% 0,611)$, Amasya Beyazı $(\% 0,592)$ ve Kozak Beyazı $(\% 0,629)$ üzüm çeşidine kıyasla daha yüksek olmuştur. İlk (ana) ürünlerde, en yüksek \%asitlik değeri Cardinal $(\% 0,643)$ üzüm çeşidinde, en düşük \%asitlik değeri ise Kozak Beyazı $(\% 0,468)$ üzüm çeşidinde tespit edilmiş, Yalova İncisi $(\% 0,575)$ ve Amasya Beyazı $(\% 0,602)$ üzüm çeşitleri ara grubu oluşturmuştur.

Olgunluk indisi parametresi incelendiğinde, Cardinal ve Kozak Beyazı üzüm çeşitlerinde ilk (ana) ürünler $(26,68$ ve 45,52$)$, ikinci ürüne $(22,69$ ve 32,70$)$ nazaran daha önemli bulunmuştur. Yalova İncisi ve Amasya Beyazı üzüm çeşitlerinde ise önemli bir farklılık oluşmamıştır. Çeşitler bazında ikinci ürünlerde en yüksek olgunluk indisini veren üzüm çeşidi Kozak Beyazı $(32,70)$ iken, en düşük değeri veren çeşit Cardinal $(22,69)$ üzüm çeşidi olmuş, Yalova İncisi $(27,61)$ ve Amasya Beyazı $(27,61)$ üzüm çeşitleri ise ara grubu oluşturmuştur. İlk (ana) ürünlerde, yine en yüksek olgunluk indisi değeri Kozak Beyazı $(45,52)$ üzüm çeşidinden, en düşük olgunluk indisi değeri Yalova İncisi $(25,09)$ üzüm çeşidinde elde edilmiş, bunu farklı bir grubu oluşturan Amasya Beyazı $(28,84)$ üzüm çeşidi takip etmiş, Cardinal $(26,68)$ üzüm çeşidi ise Amasya Beyazı ve Yalova İncisi üzüm çeşitleri arasında ara grupta yer almıştır (Çizelge 4). 
ÇOMÜ Zir. Fak. Derg. (COMU J. Agric. Fac.)

2020: 8 (1): 115-123

ISSN: $2147-8384$ / e-ISSN: 2564-6826

doi: $10.33202 /$ comuagri.660092

Çizelge 1. İlk (ana) ürün ve ikinci ürün (neferiye) salkımlarının bazı fiziksel özelliklerine ilişkin bulgular

\begin{tabular}{|c|c|c|c|c|c|c|c|c|c|c|c|c|c|}
\hline \multirow{2}{*}{ Üzüm çeşitleri } & \multirow{2}{*}{ Ürünler } & \multicolumn{4}{|c|}{ Salkım eni (cm) } & \multicolumn{4}{|c|}{ Salkım boyu (cm) } & \multicolumn{4}{|c|}{ Salkım sıklığı (1-9) } \\
\hline & & 2012 & 2013 & 2015 & Ort. & 2012 & 2013 & 2015 & Ort. & 2012 & 2013 & 2015 & Ort. \\
\hline \multirow{3}{*}{ Yalova İncisi } & İkinci ürün & $7,43 b^{*} C^{* *}$ & $9,78 \mathrm{~A}$ & $7,73 \mathrm{~b} \mathrm{~B}$ & $8,31 \mathrm{~b} \mathrm{~B}$ & $12,33 \mathrm{~b} \mathrm{~A}$ & $11,78 \mathrm{~b} \mathrm{~A}$ & 15,33 a $\mathrm{A}$ & $13,15 \mathrm{~b} \mathrm{~A}$ & $6,27 \mathrm{~A}$ & 7,67 a A & 7,00 a $\mathrm{A}$ & 6,98 a $\mathrm{A}$ \\
\hline & İlk (ana) ürün & 9,31 a B & $10,54 \mathrm{BC}$ & 9,08 a B & 9,64 a B & 16,51 a B & 17,28 a B & 13,08 b B & 15,62 a B & $6,25 \mathrm{~A}$ & $6,61 \mathrm{~b} \mathrm{~A}$ & $5,67 \mathrm{~b}$ & $6,17 \mathrm{~b} \mathrm{~A}$ \\
\hline & LSD $(\mathbf{0 , 0 5})$ & 0,631 & ÖD & 1,201 & 0,469 & 3,214 & 1,817 & 1,53 & 1,090 & ÖD & 0,426 & 0,562 & 0,358 \\
\hline \multirow{3}{*}{ Cardinal } & İkinci ürün & $6,75 \mathrm{~b} \mathrm{C}$ & $6,49 \mathrm{~b} \mathrm{C}$ & $7,30 \mathrm{~b} \mathrm{~B}$ & $6,85 \mathrm{~b} \mathrm{C}$ & $9,00 \mathrm{~b} \mathrm{~B}$ & $8,36 \mathrm{~b}$ B & $11,38 \mathrm{~b} \mathrm{~B}$ & $9,58 \mathrm{~b} \mathrm{~B}$ & $5,50 \mathrm{AB}$ & $6,21 \mathrm{~B}$ & $5,39 \mathrm{C}$ & $5,70 \mathrm{~B}$ \\
\hline & İlk (ana) ürün & 9,36 a B & 10,32 a C & 9,61 a B & 9,76 a B & 17,74 a B & 21,56 a A & 16,02 a $\mathrm{AB}$ & 18,44 a A & $5,40 \mathrm{~B}$ & $6,05 \mathrm{~B}$ & 5,49 & $5,65 \mathrm{~B}$ \\
\hline & LSD $(\mathbf{0 , 0 5})$ & 0,541 & 0,977 & 1,697 & 0,782 & 3,664 & 1,561 & 2,009 & 2,003 & ÖD & ÖD & ÖD & ÖD \\
\hline \multirow{3}{*}{ Amasya Beyazı } & İkinci ürün & $10,43 \mathrm{~A}$ & $8,24 \mathrm{~b} \mathrm{~B}$ & $9,46 \mathrm{~b} \mathrm{~A}$ & $9,38 \mathrm{~b} \mathrm{~A}$ & $12,27 \mathrm{~b} \mathrm{~A}$ & $6,73 \mathrm{~b} \mathrm{C}$ & 11,96 b B & $10,32 \mathrm{~b} \mathrm{~B}$ & $5,92 \mathrm{AB}$ & 7,73 a A & $7,21 \mathrm{a} \mathrm{A}$ & 6,95 a A \\
\hline & İlk (ana) ürün & $10,52 \mathrm{~A}$ & $11,21 \mathrm{a} A B$ & 11,40 a $\mathrm{A}$ & 11,04 a A & 17,29 a B & 19,01 a B & 17,56 a A & 17,95 a A & $5,76 \mathrm{AB}$ & $6,91 \mathrm{~b} \mathrm{~A}$ & $5,99 \mathrm{~b}$ & $6,22 \mathrm{~b} \mathrm{~A}$ \\
\hline & LSD $(0,05)$ & ÖD & 0,586 & 0,395 & 0,554 & 2,390 & 2,443 & 2,177 & 1,352 & ÖD & 0,540 & 0,579 & 0,555 \\
\hline \multirow{3}{*}{ Kozak Beyazı } & İkinci ürün & 8,85 b B & $9,65 \mathrm{~b} \mathrm{~A}$ & $8,94 \mathrm{~A}$ & $9,15 \mathrm{~b} \mathrm{~A}$ & 11,18 b AB & $8,47 \mathrm{~b} \mathrm{~B}$ & 9,89 b B & 9,85 b B & $5,07 \mathrm{~b} \mathrm{~B}$ & 7,48 a A & 6,22 a B & $6,26 \mathrm{~B}$ \\
\hline & Illk (ana) ürün & 10,64 a A & 11,43 a $\mathrm{A}$ & $10,23 \mathrm{AB}$ & 10,77 a A & 19,76 a $\mathrm{A}$ & 17,81 a B & 17,03 a A & $18,20 \mathrm{a} \mathrm{A}$ & 6,39 a $\mathrm{A}$ & $6,94 \mathrm{~b} \mathrm{~A}$ & $5,22 \mathrm{~b}$ & $6,18 \mathrm{~A}$ \\
\hline & LSD $(0,05)$ & 0,745 & 1,288 & ÖD & 0,871 & 3,029 & 2,437 & 5,672 & 2,904 & 1,109 & 0,201 & 0,964 & ÖD \\
\hline \multicolumn{2}{|c|}{ LSD $(0,05)$ neferiye } & 1,2363 & 1,1281 & 0,8605 & 0,5704 & 3,1633 & 1,4899 & 2,1525 & 1,5212 & 0,8848 & 0,7692 & 0,686 & 0,5739 \\
\hline \multicolumn{2}{|c|}{ LSD $(0,05)$ ilk (ana) ürün } & 0,4284 & 0,7352 & 1,2139 & 0,5739 & 1,8231 & 1,9668 & 3,2092 & 1,738 & 0,6894 & 0,3587 & ÖD & 0,377 \\
\hline
\end{tabular}

ÖD: Önemli değil. Ort.: Ortalama. *Küçük harfler çeșit içerisindeki neferiye ve ilk (ana) ürün arasındaki farklılı̆̆ı, **Büyük harfler ise çeșitler arasındaki neferiye ve ilk (ana) ürün arasındaki farklılığ ortaya koymaktadır.

Çizelge 2. İlk (ana) ürün ve ikinci ürün (neferiye) salkım ve tanelerinin bazı fiziksel özelliklerine ilişkin bulgular

\begin{tabular}{|c|c|c|c|c|c|c|c|c|c|}
\hline \multirow{2}{*}{ Üzüm çeşitleri } & \multirow{2}{*}{ Ürünler } & \multicolumn{4}{|c|}{ Ortalama salkım ağırlığı (g) } & \multicolumn{4}{|c|}{ Tane ağırlığı (g) } \\
\hline & & 2012 & 2013 & 2015 & Ort. & 2012 & 2013 & 2015 & Ort. \\
\hline \multirow{3}{*}{ Yalova İncisi } & İkinci ürün & $128,0 \mathrm{~b}^{*} \mathrm{~B} * *$ & $201,9 \mathrm{~b} \mathrm{~A}$ & $204,70 \mathrm{~A}$ & $156,0 \mathrm{~b} \mathrm{~A}$ & $3,48 \mathrm{~B}$ & $5,25 \mathrm{~A}$ & $3,39 \mathrm{~b} \mathrm{AB}$ & $4,04 \mathrm{~b} \mathrm{~A}$ \\
\hline & İlk (ana) ürün & 234,9 a B & 452,0 a A & $173,11 \mathrm{~B}$ & 286,7 a B & 3,59 & $6,35 \mathrm{~A}$ & 6,09 a B & 5,34 a B \\
\hline & LSD $(\mathbf{0 , 0 5})$ & 15,56 & 78,087 & ÖD & 41,37 & ÖD & ÖD & 0,230 & 0,538 \\
\hline \multirow{3}{*}{ Cardinal } & İkinci ürün & $75,02 \mathrm{~b} \mathrm{C}$ & $58,15 \mathrm{~b} \mathrm{C}$ & $80,76 \mathrm{~b} \mathrm{C}$ & $71,31 \mathrm{~b} \mathrm{~B}$ & $4,07 \mathrm{~b} \mathrm{~A}$ & $4,06 \mathrm{~b} \mathrm{~B}$ & $3,70 \mathrm{~b} \mathrm{~A}$ & $3,94 \mathrm{~b} \mathrm{~A}$ \\
\hline & İlk (ana) ürün & 238,9 a B & 365,7 a B & 224,2 a $\mathrm{AB}$ & 276,3 a B & $5,89 \mathrm{a}$ & 5,22 a B & 7,80 a $\mathrm{A}$ & 6,31 a $\mathrm{A}$ \\
\hline & LSD $(\mathbf{0 , 0 5})$ & 22,205 & 44,399 & 82,83 & 37,41 & 0,263 & 0,409 & 1,064 & 0,297 \\
\hline \multirow{3}{*}{ Amasya Beyazı } & İkinci ürün & $187,7 \mathrm{~A}$ & $110,7 \mathrm{~b}$ B & $162,9 \mathrm{~b}$ B & $153,8 \mathrm{~b} \mathrm{~A}$ & 3,17 a B & $3,60 \mathrm{~b} \mathrm{~B}$ & $3,28 \mathrm{~b} \mathrm{AB}$ & $3,35 \mathrm{~b} \mathrm{~B}$ \\
\hline & İlk (ana) ürün & $203,4 \mathrm{~B}$ & 420,4 a $\mathrm{AB}$ & 316,1 a $\mathrm{A}$ & 313,3 a B & $2,51 \mathrm{~b}$ & 4,82 a C & 5,03 a C & 4,12 a C \\
\hline & LSD $(0,05)$ & ÖD & 64,78 & 42,883 & 20,46 & 0,259 & 0,775 & 0,819 & 0,309 \\
\hline \multirow{3}{*}{ Kozak Beyazı } & İkinci ürün & $113,2 \mathrm{~b} \mathrm{~B}$ & $169,4 \mathrm{~b} \mathrm{~A}$ & 130,8 b B & $137,8 \mathrm{~b} \mathrm{~A}$ & $3,07 \mathrm{~B}$ & $5,48 \mathrm{~A}$ & 3,06 b B & $3,87 \mathrm{~b} \mathrm{~A}$ \\
\hline & İlk (ana) ürün & 305,1 a A & 494,9 a A & 279,7 a A & 359,9 a A & 2,78 & $6,37 \mathrm{~A}$ & 6,73 a B & 5,29 a B \\
\hline & $\operatorname{LSD}(\mathbf{0 , 0 5})$ & 95,427 & 106,67 & 147,14 & 62,00 & ÖD & ÖD & 0,349 & 0,159 \\
\hline \multicolumn{2}{|c|}{ LSD $(0,05)$ neferiye } & 32,045 & 36,648 & 37,587 & 24,313 & 0,4806 & 0,9536 & 0,4575 & 0,3578 \\
\hline \multicolumn{2}{|c|}{ LSD $(0,05)$ ilk (ana) ürün } & 53,795 & 82,536 & 100,51 & 44,186 & & 0,392 & 0,6875 & 0,2095 \\
\hline
\end{tabular}

ÖD: Önemli değil. Ort.: Ortalama. *Küçük harfler çeşit içerisindeki neferiye ve ilk (ana) ürün arasındaki farklılı̆̆ı **Büyük harfler ise çeşitler arasındaki neferiye ve ilk (ana) ürün arasındaki farklılı̆̆ 
ÇOMÜ Zir. Fak. Derg. (COMU J. Agric. Fac.)

2020: 8 (1): $115-123$

ISSN: $2147-8384$ / e-ISSN: $2564-6826$

doi: $10.33202 /$ comuagri.660092

Çizelge 3. İlk (ana) ürün ve ikinci ürün (neferiye) tanelerinin bazı kimyasal özelliklerine ilişkin bulgular

\begin{tabular}{|c|c|c|c|c|c|c|c|c|c|}
\hline \multirow{2}{*}{ Üzüm çeşitleri } & \multirow{2}{*}{ Ürünler } & \multicolumn{4}{|c|}{ \%SÇKM } & \multicolumn{4}{|c|}{ pH } \\
\hline & & 2012 & 2013 & 2015 & Ort. & 2012 & 2013 & 2015 & Ort. \\
\hline \multirow{3}{*}{ Yalova İncisi } & İkinci ürün & $15,12 \mathrm{C}$ & $17,12 \mathrm{a} * \mathrm{~B} * *$ & $14,27 \mathrm{~B}$ & $15,50 \mathrm{a} \mathrm{C}$ & $3,49 \mathrm{~B}$ & $3,71 \mathrm{~A}$ & 3,55 & $3,58 \mathrm{~A}$ \\
\hline & İlk (ana) ürün & $13,59 \mathrm{C}$ & $14,00 \mathrm{~b} \mathrm{C}$ & $15,00 \mathrm{D}$ & $14,20 \mathrm{~b} \mathrm{C}$ & $3,58 \mathrm{~B}$ & $3,65 \mathrm{~B}$ & $3,62 \mathrm{~B}$ & $3,62 \mathrm{~B}$ \\
\hline & LSD $(\mathbf{0 , 0 5})$ & ÖD & 1,662 & ÖD & 0,7008 & ÖD & ÖD & ÖD & ÖD \\
\hline \multirow{3}{*}{ Cardinal } & İkinci ürün & $18,97 \mathrm{~A}$ & $16,70 \mathrm{a} B$ & $15,87 \mathrm{~b} \mathrm{~B}$ & $17,18 \mathrm{a} B$ & $3,63 \mathrm{~b} \mathrm{~A}$ & $3,39 \mathrm{~B}$ & $3,40 \mathrm{~b}$ & $3,47 \mathrm{~b} \mathrm{~B}$ \\
\hline & İlk (ana) ürün & $18,60 \mathrm{~A}$ & $13,93 \mathrm{~b} \mathrm{C}$ & $16,40 \mathrm{a} \mathrm{C}$ & $16,31 \mathrm{~b} \mathrm{~B}$ & $3,74 \mathrm{a} \mathrm{A}$ & $3,46 \mathrm{C}$ & $3,85 \mathrm{a} \mathrm{A}$ & $3,69 \mathrm{a} B$ \\
\hline & LSD $(0,05)$ & ÖD & 1,757 & 0,463 & 0,545 & 0,0524 & ÖD & 0,1126 & 0,0571 \\
\hline \multirow{3}{*}{ Amasya Beyazı } & İkinci ürün & $16,08 \mathrm{BC}$ & $16,90 \mathrm{~B}$ & $15,10 \mathrm{~b} \mathrm{~B}$ & $16,03 \mathrm{C}$ & $3,47 \mathrm{~B}$ & $3,42 \mathrm{~B}$ & $3,48 \mathrm{~b}$ & $3,46 \mathrm{~b} \mathrm{~B}$ \\
\hline & İlk (ana) ürün & $15,31 \mathrm{~B}$ & $16,53 \mathrm{~B}$ & $18,43 \mathrm{a} \mathrm{B}$ & $16,76 \mathrm{~B}$ & $3,56 \mathrm{~B}$ & $3,57 \mathrm{~B}$ & $3,92 \mathrm{a} \mathrm{A}$ & $3,68 \mathrm{a} B$ \\
\hline & LSD $(0,05)$ & ÖD & ÖD & 1,676 & ÖD & ÖD & ÖD & 0,1968 & 0,0774 \\
\hline \multirow{3}{*}{ Kozak Beyazı } & İkinci ürün & $17,27 \mathrm{~B}$ & $20,37 \mathrm{~A}$ & $18,20 \mathrm{~A}$ & $18,61 \mathrm{~b} \mathrm{~A}$ & $3,47 \mathrm{~b} \mathrm{~B}$ & $3,63 \mathrm{~b} \mathrm{~A}$ & $3,49 \mathrm{~b}$ & $3,53 \mathrm{~b} \mathrm{AB}$ \\
\hline & İlk (ana) ürün & $18,46 \mathrm{~A}$ & $22,21 \mathrm{~A}$ & $20,43 \mathrm{~A}$ & $20,37 \mathrm{a} A$ & $3,57 \mathrm{a} B$ & $3,86 \mathrm{a} A$ & 3,90a A & $3,77 \mathrm{a} \mathrm{A}$ \\
\hline & LSD $(\mathbf{0 , 0 5})$ & ÖD & ÖD & ÖD & 1,6849 & 0,0868 & 0,1792 & 0,2512 & 0,1103 \\
\hline \multicolumn{2}{|c|}{ LSD $(0,05)$ neferive } & 1,3039 & 1,9176 & 2,1523 & 1,1324 & 0,1425 & 0,1822 & ÖD & 0,0859 \\
\hline \multicolumn{2}{|c|}{ LSD $(0,05)$ ilk (ana) ürün } & 1,5877 & 0,9391 & 1,167 & 0,5512 & 0,0913 & 0,0824 & 0,1683 & 0,0806 \\
\hline
\end{tabular}

ÖD: Önemli değil. Ort.: Ortalama *Küçük harfler çeşit içerisindeki neferiye ve ilk (ana) ürün arasındaki farklılığı, **Büyük harfler ise çeşitler arasındaki neferiye ve ilk (ana) ürün arasındaki farklılı̆̆1 ortaya koymaktadır.

Çizelge 4. İlk (ana) ürün ve ikinci ürün (neferiye) tanelerindeki bazı kimyasal özelliklere ilişkin bulgular

\begin{tabular}{|c|c|c|c|c|c|c|c|c|c|}
\hline \multirow{2}{*}{ Üzüm çeşitleri } & \multirow{2}{*}{ Ürünler } & \multicolumn{4}{|c|}{ \%asitlik } & \multicolumn{4}{|c|}{ Olgunluk indisi (\%SÇKM/\%asitlik) } \\
\hline & & 2012 & 2013 & 2015 & Ort. & 2012 & 2013 & 2015 & Ort. \\
\hline \multirow{3}{*}{ Yalova İncisi } & İkinci ürün & 0,657 & $0,426 b^{*} C^{* *}$ & $0,747 \mathrm{~B}$ & $0,611 \mathrm{~B}$ & 23,60 & $40,02 \mathrm{a} A$ & 19,22 & $27,61 \mathrm{AB}$ \\
\hline & İlk (ana) ürün & $0,515 \mathrm{~B}$ & $0,540 \mathrm{a} \mathrm{C}$ & $0,670 \mathrm{~A}$ & $0,575 \mathrm{~B}$ & $26,68 \mathrm{~B}$ & $26,17 \mathrm{~b} \mathrm{~B}$ & $22,40 \mathrm{C}$ & $25,09 \mathrm{C}$ \\
\hline & LSD $(0,05)$ & ÖD & 0,0686 & ÖD & ÖD & ÖD & 7,1630 & ÖD & ÖD \\
\hline \multirow{3}{*}{ Cardinal } & İkinci ürün & $0,609 \mathrm{a}$ & $0,779 \mathrm{~A}$ & $1,062 \mathrm{a} \mathrm{A}$ & $0,816 \mathrm{a} A$ & 31,36 & $21,64 \mathrm{~B}$ & $15,08 \mathrm{~b}$ & $22,69 \mathrm{~b} \mathrm{~B}$ \\
\hline & İlk (ana) ürün & $0,512 \mathrm{~b} \mathrm{~B}$ & $0,790 \mathrm{~A}$ & $0,630 \mathrm{~b} \mathrm{AB}$ & $0,643 \mathrm{~b} \mathrm{~A}$ & $36,38 \mathrm{~A}$ & $17,63 \mathrm{C}$ & $26,03 \mathrm{a} \mathrm{C}$ & $26,68 \mathrm{a} B C$ \\
\hline & LSD $(0,05)$ & 0,0838 & ÖD & 0,2539 & 0,0822 & ÖD & ÖD & 3,0139 & 1,7039 \\
\hline \multirow{3}{*}{ Amasya Beyazı } & İkinci ürün & 0,533 & $0,600 \mathrm{~B}$ & $0,643 \mathrm{~B}$ & $0,592 \mathrm{~B}$ & 30,32 & $28,69 \mathrm{~B}$ & $23,82 b$ & $27,61 \mathrm{AB}$ \\
\hline & İlk (ana) ürün & $0,594 \mathrm{~A}$ & $0,670 \mathrm{~B}$ & $0,540 \mathrm{BC}$ & $0,602 \mathrm{~B}$ & $26,45 \mathrm{~B}$ & $25,76 \mathrm{~B}$ & $34,30 \mathrm{a} B$ & $28,84 \mathrm{~B}$ \\
\hline & LSD $(\mathbf{0 , 0 5})$ & ÖD & ÖD & ÖD & ÖD & ÖD & ÖD & 8,0058 & ÖD \\
\hline \multirow{3}{*}{ Kozak Beyazı } & İkinci ürün & $0,659 \mathrm{a}$ & $0,443 \mathrm{a} \mathrm{C}$ & $0,790 \mathrm{AB}$ & 0,629 a B & $26,30 \mathrm{~b}$ & $46,60 \mathrm{~b} \mathrm{~A}$ & 25,19 & $32,70 \mathrm{~b} \mathrm{~A}$ \\
\hline & İlk (ana) ürün & $0,530 \mathrm{~b} \mathrm{~B}$ & $0,380 \mathrm{~b} \mathrm{D}$ & $0,496 \mathrm{C}$ & $0,468 \mathrm{~b} \mathrm{C}$ & $35,82 \mathrm{a} \mathrm{A}$ & $59,17 \mathrm{a} \mathrm{A}$ & $41,59 \mathrm{~A}$ & $45,52 \mathrm{a} \mathrm{A}$ \\
\hline & LSD $(\mathbf{0 , 0 5})$ & 0,1171 & 0,0607 & ÖD & 0,117 & 8,0724 & 11,061 & ÖD & 6,6381 \\
\hline \multicolumn{2}{|c|}{ LSD $(0,05)$ neferiye } & ÖD & 0,1138 & 0,2837 & 0,1101 & ÖD & 9,644 & ÖD & 5,2721 \\
\hline \multicolumn{2}{|c|}{ LSD $(0,05)$ ilk (ana) ürün } & 0,061 & 0,0549 & 0,1127 & 0,0417 & 5,632 & 3,4904 & 6,4344 & 2,996 \\
\hline
\end{tabular}

ÖD: Önemli değil. Ort.: Ortalama *Küçük harfler çeşit içerisindeki neferiye ve ilk (ana) ürün arasındaki farklılığı, **Büyük harfler ise çeșitler arasındaki neferiye ve ilk (ana) ürün arasındaki

farklılığı ortaya koymaktadır. 


\section{Sonuç ve Öneriler}

Sofralık üzüm çeşitlerinde ikinci ürün (neferiye) salkımlarının bazı genel karakteristiklerinin belirlenmesi amacıyla 2012, 2013 ve 2015 yıllarında yürütülmüş olan bu araştırmanın bazı önemli sonuçları aşağıda özetlenmiştir.

Üzüm çeşitlerinin ilk (ana) ürün ve ikinci ürün (neferiye) salkımlarının karşılaştırılması sonucunda salkım eni $(\mathrm{cm})$, salkım boyu $(\mathrm{cm})$, salkım sıklığ $1(1-9)$, ortalama salkım ağırlı $\breve{g}_{1}(\mathrm{~g})$, tane ağırlı̆̆ $(\mathrm{g})$ \% \%ÇKM, pH, \%asitlik ve olgunluk indisi (\%SÇKM/\%asitlik) parametrelerinde önemli farklılıkların oluştuğu saptanmıştır.

Yürütülmüş olan bu araştırmadaki ortalamalar veriler değerlendirildiğinde; Yalova İncisi, Cardinal, Amasya Beyazı ve Kozak Beyazı üzüm çeşitlerinde salkım eni, salkım boyu, ortalama salkım ağırlığı ve tane ağırlığındaki en yüksek değerlerin ilk (ana) ürünlerden alındığı tespit edilmiştir. Salkım eni, salkım boyu, ortalama salkım ağırlığı ve tane ağırlığı değerlerine göre ilk (ana) ürünlerin, ikinci ürünlere kıyasla daha iri salkım ve taneler oluşturduğu sonucuna varılmıştır. Ancak ikinci ürünlere ait salkımların yapıları, ilk (ana) ürünlere kıyasla daha sıkı olmuştur.

Yalova İncisi ve Cardinal üzüm çeşitlerinde en yüksek \%SÇKM değeri ikinci ürünlerden elde edilirken, Kozak Beyazı üzüm çeşidinde ilk (ana) ürünlerde tespit edilmiştir. Cardinal, Amasya Beyazı ve Kozak Beyazı üzüm çeşitlerinin ilk (ana) ürünlerine ait $\mathrm{pH}$ değerleri ikinci ürünlere kıyasla önem oluşturmuştur. Cardinal ve Kozak Beyazı üzüm çeşitlerinde en yüksek \%asitlik değerleri ikinci ürünlerden elde edilmiştir. Cardinal ve Kozak Beyazı üzüm çeşitlerinde ilk (ana) ürünlerin olgunluk indisi değerleri, ikinci ürünlerin olgunluk indisi değerlerine nazaran önemli düzeyde yüksek bulunmuştur.

Üzüm çeşitleri arasında ikinci ürünlerin (neferiye) salkımlarına ait ortalama veriler incelendiğinde; salkım eni bakımından Amasya Beyazı ve Kozak Beyazı üzüm çeşitleri, Yalova İncisi ve Cardinal üzüm çeşitlerine kıyasla daha enli olmuştur. Salkım boyu parametresinde en uzun salkımlar Yalova İncisi üzüm çeşidinden elde edilmiş, bunu sırasıyla Amasya Beyazı, Kozak Beyazı ve Cardinal üzüm çeşitleri takip etmiştir. Yalova İncisi ve Amasya Beyazı üzüm çeşitlerinin ikinci ürün salkımları, Cardinal ve Kozak Beyazı üzüm çeşitlerine kıyasla daha sık salkım oluşturmuştur. İkinci ürünlerde en yüksek ortalama salkım ağırlığına sahip çeşitler sırasıyla Yalova İncisi, Amasya Beyazı ve Kozak Beyazı iken, en hafif salkımlar ise Cardinal üzüm çeşidinden elde edilmiştir. İkinci ürünlerdeki en ağır taneleri sırasıyla Yalova İncisi, Cardinal ve Kozak Beyazı üzüm çeşitleri meydana getirmiştir.

Üzüm çeşitleri arasında ikinci ürünlerin (neferiye) tanelerindeki bazı kimyasal özelliklere ait ortalama verilere bakıldığında; en yükssek \%SÇKM değeri Kozak Beyazı üzüm çeşidinde, en düşük \%SÇKM değeri Yalova İncisi ve Amasya Beyazı üzüm çeşitlerinde tespit edilmiştir. Olgunluk indisinde Kozak Beyazı üzüm çeşidinden en yüksek, Cardinal üzüm çeşidinden en düşük değer tespit edilmiştir.

Sonuç olarak; ikinci ürün (neferiye) salkımlarının ilk (ana) ürüne kıyasla en, boy ve ağırlık olarak daha küçük, daha sık ve hafif taneli oldukları saptanmıştır. İkinci ürün (neferiye) hakkında yapılmış yeterince araştırma olmadığından, konu üzerinde daha fazla çalışma yapılması gerekliliği bulunmakta ve bu araştırmanın sonraki çalışmalara zemin hazırlayacağı düşünülmektedir.

Not: Bu araştırmadaki emeklerinden dolayı, Zir. Yük. Müh. Çiğdem Altın'a ve Zir. Müh. Meryem Karadağ’a teşekkürlerimizi sunarız.

\section{Kaynaklar}

Ağaoğlu, Y.S., 1969. Şaraplık üzüm çeşitlerinden Hasandede, Kalecik karası, Papaz karası, Öküzgözü ve Furmint'in tomurcuk yapıları, floral gelişme devrelerinin tetkiki ve bu çeşitlere uygun budama metotlarının tespiti üzerinde mukayeseli araştırmalar. Ankara Üniversitesi Ziraat Fakültesi (Basılmamış doktora tezi). $297 \mathrm{~s}$. Ankara.

Ağaoğlu, Y.S., 1999. Bilimsel ve Uygulamalı Bağcılık (Cilt I Asma Biyolojisi). Kavaklıdere Eğitim Yayınları No: 1. 205 s. Ankara.

Ağaoğlu, Y.S., 2002. Bilimsel ve Uygulamalı Bağcılık (Cilt II Asma Fizyolojisi-I). Kavaklıdere Eğitim Yayınları No: 5.445 s. Ankara.

Anonim, 1985. Descriptor List for Grapevine Varieties and Vitis Species. Office International de la vigne et de Vin, Paris. 
Antcliff, A.J., 1958. Studies on the Sultana vine. IV. The morphology of canes and its fruitfulness, Austral. Agric. Res. 9: 328-338.

Çelik, H., Ağaoğlu, Y.S., Fidan, Y., Marasalı, B., Söylemezoğlu, G., 1998. Genel Bağcılık. (Birinci baskı) Sun Fidan A.Ş. Mesleki Kitaplar Serisi: 1. 253 s. Ankara.

Çelik, S., 2011. Bağcılık (Ampeloloji). Cilt I, 3. Baskı. Namık Kemal Üniversitesi. Ziraat Fakültesi Bahçe Bitkileri Bölümü. 428 s. Tekirdağ.

Dardeniz, A., 2011. Asmanın morfolojik yapısı 3. 72 s. (Basılmamış ders notları).

Kısmalı, İ., Ilgın, C., 1992. Yuvarlak Çekirdeksiz üzüm çeşidinde budamada bırakılan koltuklu dalların verimliliği üzerinde araştırmalar. Türkiye I. Ulusal Bahçe Bitkileri Kongresi. Cilt II. 569-571.

Koblet, W., Perret, P., 1971. Dei bedeutung der geitztriebe bei beren obst und weinbau. 107(15): 462-464.

Scheu, G., 1950. Mein Winzerbuch. Verlag Paul Parey. Berlin.

Sezen, E., Dardeniz, A., 2015. Farklı kış budama dönemleri ve yaz budaması uygulamalarının Yalova İncisi üzüm çeşidinin verim ve kalitesine olan etkilerinin belirlenmesi. ÇOMÜ Zir. Fak. Derg. 3(1): 15-27.

Türker, L., Dardeniz, A., 2014. Sofralık üzüm çeşitlerinde farklı düzeylerdeki koltuk alma uygulamalarının verim ve kalite özellikleri üzerindeki etkileri. ÇOMÜ Zir. Fak. Derg. 2(2): 73-82.

Winkler, A.J., Cook, J.A., Kliewer, W.M., Lider, L.A., 1974. General Viticulture. $2^{\text {nd }}$ Edition, University of California

Press. 710

p.

Berkeley 